aspect of what is more like ruthless marketing and commerce than medicine refined by responsible, ethical conduct.

DEPARTMENT OF HEALTH (2004) Internationa Fellowship Scheme (http://fellowships.tmpw.co.uk/ index.asp).

KHAN, M. M. (2004) The NHS International Fellowship Scheme in Psychiatry: robbing the poor to pay the rich? Psychiatric Bulletin, 28, 435-437.

GOLDBERG, D. (2004) The NHS International Fellowship Scheme in Psychiatry, Reply to Khan. Psychiatric Bulletin, 28, 433-434.

WORLD HEALTH ORGANIZATION (2001) Atlas of Country Profiles of Mental Health Resources. Geneva: $\mathrm{WHO}$

R. Haghighat Medical Sociologist and Independent Psychiatrist and Psychotherapist, c/o The Royal College of Psychiatrists, 17 Belgrave Square, London SW1X 8PG (e-mail: r.haghighat@lycos.com)

\section{Annual Review 2004}

The President's foreword to the Annual Review 2004 proposes transformation of the Royal College to a 'College of Menta Health' with open membership.
Dr Shooter's 'vision' colludes with a politically correct agenda of a 'wants-' rather than a needs-based service.

I would suggest it is time for members and fellows to defend the name and values of the College, including entrance protected by examination.

K. D. Williams Consultant Psychiatrist, North Gloucester Community Mental HealthTeams, 18 Denmark Road, Gloucester GL13HZ

\section{Physical health and health risk factors in a population of long-stay psychiatric patients}

I was interested to read Dr Cormac et al's article regarding physical health and health risk factors in a population of longstay psychiatric patients (Psychiatric Bulletin, January 2005, 29, 18-20). In my own service I am responsible for two long-stay units. Local general practitioners (GPs) have designated sessions to attend consultant ward-round reviews and are responsible for providing primary care services for patients in these units. This means that as part of the regular review, issues such as weight gain and diet, smoking, hypertension and other risk factors predisposing to coronary heart disease or other physical disorders are regularly discussed and addressed with appropriate physical examination, healthcare advice and investigations.

The value of GPs attending the regular in-patient reviews has offered benefit not only to our residents in ensuring appropriate access to primary care services, but also to myself and staff in learning about recent initiatives in primary care. The GPs who attend have also had the benefit of access to the knowledge and experience of mental health specialists, which they have been able to use in their own practice.

It would seem a mutually beneficial arrangement and one that I would recommend to all services that provide long-stay, psychiatric in-patient services.

G. L. Milner Consultant Psychiatrist, Birmingham and Solihull Mental Health NHS Trust, 51 Grove Road, Solihull, West Midlands B912AQ 